\title{
Why Do Physicians Pursue Cascades of Care After Incidental Findings? A National Survey
}

\author{
Ishani Ganguli, MD, MPH ${ }^{\top} \mathbb{0}$, Arabella L. Simpkin, MD, MMSc ${ }^{7}$, Carrie H. Colla, $P h D^{2}$, \\ Arlene Weissman, $\mathrm{PhD}^{3}$, Alexander J. Mainor, JD, MPH², Meredith B. Rosenthal, $\mathrm{PhD}^{4}$, \\ and Thomas $D$. Sequist, $M D, M P H^{7}$
}

'Harvard Medical School, Boston, MA, USA; ${ }^{2}$ Geisel School of Medicine at Dartmouth, NH, Lebanon, USA; ${ }^{3}$ American College of Physicians, Philadelphia, PA, USA; ${ }^{4}$ Harvard T. H. Chan School of Public Health, Boston, MA, USA.

$\mathrm{J}$ Gen Intern Med 35(4):1352-4

DOI: $10.1007 / \mathrm{s} 11606-019-05213-1$

(c) Society of General Internal Medicine 2019

\section{INTRODUCTION}

Screening and diagnostic tests often reveal incidental findings, prompting cascades of further testing and treatment that are of uncertain value and can cause financial, physical, and psychological harms. ${ }^{1,2}$ Like medical decisions writ large, the decision to pursue equivocal incidental findings may vary across physicians-informed not just by clinical need but also by physician factors such as training, fear of liability, discomfort with uncertainty, cost-consciousness, and perceived patient demand, or by health system factors such as malpractice laws and community norms. ${ }^{1,}{ }^{3}$ Understanding how often and why doctors make these decisions would help to mitigate harms from cascades. Therefore, we surveyed a national sample of generalist physicians to explore variation in, predictors of, and motivations behind the decision to pursue equivocal incidental findings.

\section{METHODS}

We used prior literature and cognitive interviews to develop a survey instrument that included two clinical vignettes as well as items on respondent characteristics and one's most recently experienced cascade from any incidental finding. We administered the web-based survey to a stratified random sample of American College of Physician (ACP) members (residents, fellows, internists, and geriatricians actively practicing outpatient medicine) between January 22 and March 3, 2019.

Our primary outcomes were vignette-based decisions to pursue evaluation of an equivocal incidental finding when (a) guidelines did not recommend testing but a specialist did (Vignette 1), or (b) there was no guiding evidence (Vignette 2) (Table 1). We fit logistic regression models using these

Received July 1, 2019

Accepted July 11, 2019

Published online July 25, 2019

outcomes and the following predictors: age, sex, geographic region, practice setting, area-level education, trainee versus attending status, foreign versus US medical training, time in direct patient care, malpractice history, personal experience of cascade as a patient, and validated cost-consciousness and discomfort with uncertainty scales. We also examined selfreported reasons to pursue further testing during one's most recently experienced cascade. We weighted all responses to be nationally representative. We used STATA 14.2 (STATA Corp., College Station, TX) and considered 2-tailed $p$ values significant at $p<0.05$. Partners Institutional Review Board approved this study.

Table 1 Vignette-Based Questions About Evaluation of Equivocal Incidental Findings

Vignette 1: Your patient is a healthy 60-year-old man with no prior history of smoking or cancer. Before knee surgery, he receives a routine preoperative chest $x$-ray that shows a pulmonary nodule. The radiology report for the follow-up chest computed tomography (CT) scan confirms a $5 \mathrm{~mm}$ nodule and instructs you to "repeat chest CT in 6-12 months." The 2017 Fleischner Society guidelines recommend no further action. In addition to speaking with your patient, what would you do next?

$\begin{array}{ll}\text { Response } & \begin{array}{l}\text { Respondents, \% } \\ \mathbf{N = 3 7 6}\end{array} \\ \begin{array}{l}\text { Repeat chest CT in 6-12 months } \\ \text { Refer patient for consultation with pulmonology }\end{array} & 3.7 \\ \begin{array}{l}\text { or thoracic surgery } \\ \text { Make a decision after speaking with a radiologist, } \\ \text { pulmonologist, or thoracic surgeon }\end{array} & 17.3 \\ \text { No further action per guidelines } & 41.7\end{array}$

Vignette 2: Your patient is a healthy 30-year-old woman. Before knee surgery, she receives a routine preoperative complete blood count that is normal except for Hemoglobin $11.2 \mathrm{~g} / \mathrm{dL}$ (Reference range $11.5-16.4 \mathrm{~g}$ / $d L$ ) and Hematocrit 35.0 (Reference range $36.0-48.0 \%$ ). In addition to speaking with your patient, what would you do next?

Response

Repeat complete blood count in 1-4 weeks Order further tests such as stool guaiac, iron studies, vitamin $\mathrm{B}_{12}$, folate, reticulocyte count, or peripheral smear

Refer to hematology

No further action (result may be due to menstrual blood loss, for example)

Values are weighted percentages. Pursuing an incidental finding was defined as choosing any option besides "no further action" for a given vignette 
Table 2 Physician, Practice, and Area-Level Predictors of Pursuing Equivocal Incidental Findings

\begin{tabular}{|c|c|c|c|c|c|}
\hline \multirow[t]{2}{*}{ Characteristic } & & \multicolumn{2}{|c|}{ Vignette 1 (pulmonary nodule) } & \multicolumn{2}{|c|}{ Vignette 2 (borderline anemia) } \\
\hline & & OR $(95 \% \mathrm{CI})$ & $\begin{array}{l}\text { Adjusted OR } \\
(95 \% \mathrm{CI})^{\%}\end{array}$ & OR $(95 \% \mathrm{CI})$ & $\begin{array}{l}\text { Adjusted OR } \\
(95 \% \mathrm{CI})^{\uparrow}\end{array}$ \\
\hline Age & $\begin{array}{l}\leq 39 \\
40-55 \\
\geq 56\end{array}$ & $\begin{array}{l}1[\text { Reference }] \\
1.29(0.74,2.26) \\
1.57(0.96,2.58)\end{array}$ & $\begin{array}{l}0.77(0.34,1.79) \\
0.99(0.41,2.40)\end{array}$ & $\begin{array}{l}1.39(0.80,2.41) \\
1.85(1.11,3.08)^{\#}\end{array}$ & $\begin{array}{l}0.60(0.25,1.43) \\
0.67(0.27,1.69)\end{array}$ \\
\hline Sex* & $\begin{array}{l}\text { Female } \\
\text { Male }\end{array}$ & $\begin{array}{l}1[\text { Reference }] \\
0.85(0.53,1.35)\end{array}$ & $0.98(0.60,1.59)$ & $1.47(0.92,2.35)$ & $1.47(0.90,2.40)$ \\
\hline Medical school training & $\begin{array}{l}\text { USA } \\
\text { Foreign }\end{array}$ & $\begin{array}{l}1[\text { Reference }] \\
0.58(0.35,0.97)^{\#}\end{array}$ & $0.58(0.34,0.98)^{\#}$ & $0.89(0.53,1.49)$ & $1.04(0.60,1.79)$ \\
\hline Status & $\begin{array}{l}\text { Resident } \\
\text { Fellow } \\
\text { Attending }\end{array}$ & $\begin{array}{l}1[\text { Reference }] \\
1.47(0.56,3.85) \\
1.60(0.99,2.61)\end{array}$ & $\begin{array}{l}1.49(0.55,4.05) \\
1.65(0.70,3.90)\end{array}$ & $\begin{array}{l}0.89(0.34,2.31) \\
1.86(1.13,3.04)^{\#}\end{array}$ & $\begin{array}{l}1.13(0.41,3.09) \\
2.35(0.96,5.75)\end{array}$ \\
\hline Practice setting & $\begin{array}{l}\text { Urban } \\
\text { Rural } \\
\text { Suburban }\end{array}$ & $\begin{array}{l}1[\text { Reference }] \\
0.81(0.38,1.72) \\
1.17(0.73,1.88)\end{array}$ & $\begin{array}{l}0.78(0.36,1.70) \\
0.97(0.59,1.58)\end{array}$ & $\begin{array}{l}2.18(0.96,4.96) \\
1.47(0.91,2.38)\end{array}$ & $\begin{array}{l}1.64(0.72,3.75) \\
1.22(0.73,2.02)\end{array}$ \\
\hline Geographic region $^{\dagger}$ & $\begin{array}{l}\text { Nuburban } \\
\text { Midweast } \\
\text { Mouth } \\
\text { West }\end{array}$ & $\begin{array}{l}1.1 /(\text { Reference }] \\
0.76(0.40,1.47) \\
0.60(0.33,1.11) \\
1.62(0.83,3.18)\end{array}$ & $\begin{array}{l}0.89(0.47,1.70) \\
0.65(0.36,1.18) \\
1.29(0.66,2.51)\end{array}$ & $\begin{array}{l}1.05(0.53,2.05) \\
0.92(0.49,1.73) \\
0.82(0.42,1.59)\end{array}$ & $\begin{array}{l}0.85(0.43,1.67) \\
1.02(0.54,1.90) \\
0.74(0.38,1.44)\end{array}$ \\
\hline Area-level education & $\begin{array}{l}<90 \% \text { with high school education } \\
\geq 90 \% \text { with high school education }\end{array}$ & $\begin{array}{l}1[\text { Reference] } \\
1.52(0.96,2.41)\end{array}$ & $1.22(0.76,1.96)$ & $1.93(1.20,3.09)^{\#}$ & $1.60(0.99,2.60)$ \\
\hline Time in direct patient care & $\begin{array}{l}\leq 49 \% \\
50-74 \% \\
\geq 75 \%\end{array}$ & $\begin{array}{l}1[\text { Reference] } \\
1.38(0.59,3.25) \\
1.89(0.99,3.64)\end{array}$ & $\begin{array}{l}1.04(0.45,2.41) \\
1.40(0.72,2.71)\end{array}$ & $\begin{array}{l}1.29(0.54,3.09) \\
1.27(0.66,2.47)\end{array}$ & $\begin{array}{l}1.71(0.71,4.11) \\
1.34(0.68,2.63)\end{array}$ \\
\hline Prior malpractice lawsuit & Never & 1 [Reference] & & $179(1.07 \quad 298)^{\#}$ & \\
\hline $\begin{array}{l}\text { Personal experience of cas } \\
\text { Discomfort with uncertain } \\
\text { Cost-consciousness scale ( }\end{array}$ & scale $(1-6)^{\S}$ & $\begin{array}{l}0.91(0.58,1.44) \\
1.05(0.89,1.25) \\
0.96(0.92,1.00)\end{array}$ & $\begin{array}{l}1.04(0.66,1.64) \\
1.03(0.86,1.22){ }^{\#} \\
0.95(0.90,0.99)^{\#}\end{array}$ & $\begin{array}{l}0.72(0.45,1.15) \\
0.86(0.72,1.03) \\
1.02(0.98,1.07)\end{array}$ & $\begin{array}{l}0.74(0.47,1.18) \\
0.88(0.74,1.06) \\
1.01(0.96,1.05)\end{array}$ \\
\hline
\end{tabular}

*Data missing for 11 respondents

${ }^{\dagger}$ Based on Census region linked to physician-reported practice zip code. Census region data were not available for zip codes reported by 6 physicians in the sample

${ }^{7}$ Area-level education derived using the American Community Survey linked to physician-reported practice zip code. Area-level education data were not available for zip codes reported by 18 physicians in the sample

${ }^{3}$ The discomfort with uncertainty scale ranged from 1 to 6 , with 6 signifying the greatest discomfort

"To create the cost-consciousness scale, we reversed items with negative wording to ensure that a higher score meant greater cost-consciousness, then calculated summary scores by summing the responses (6-36, 36 denoted most discomfort)

${ }^{\top}$ Multivariable logistic regression models were built using all covariates represented in the table. The primary outcome was physician-reported decision to pursue cascade (defined as any response other than "no further action" for a given vignette). Physicians with any missing data $(<5 \%)$ were excluded from these models

${ }^{\#}$ Statistically significant at $p<0.05$

\section{RESULTS}

Response rate was 44.7\% ( $n=376$; American Association for Public Opinion Research definition 3). When responding to clinical vignettes, $57.6 \%$ of physicians reported they would follow a specialist's recommendations over guidelines; $62.4 \%$ would do further testing in the absence of guiding evidence (Table 1). In multivariable models, US medical graduates and less cost-conscious physicians were more likely to pursue specialist-recommended testing discordant with guidelines (Table 2).

When reflecting on their most recent cascade, 364 respondents reported that they personally pursued follow-up of the incidental finding and $58.6 \%$ of these respondents did so because it "seemed clinically important." Of the remaining $41.4 \%$, the most common reasons to pursue follow-up were practice/community norms (49.7\%), concern about a lawsuit (35.7\%), another doctor's advice (26.0\%), and patient request (24.2\%) (not mutually exclusive). Doctors who had experienced a lawsuit were more likely than those who had not to report they pursued follow-up testing out of concern about another lawsuit $(44.3 \%$ vs $27.6 \%, p=0.002)$.

\section{DISCUSSION}

Many physicians reported they would pursue equivocal incidental findings contrary to or in the absence of evidence, yet several plausible factors such as experience or discomfort with uncertainty did not predict these decisions. Less cost-conscious and US-trained physicians were more likely to pursue guideline-discordant follow-up, which may reflect their values and training in relatively resource-rich settings, respectively. The lack of other significant predictors mirrors claims-based studies on lowvalue care ${ }^{4}$ and points to unmeasured traits like physicians' statistical knowledge ${ }^{1}$ or their working relationships with radiologists that might be explored further. ${ }^{3}$

Our findings also underscore that physicians often feel compelled to pursue cascades after an incidental finding, whether or not it is clinically needed. ${ }^{1,3}$ When recalling their most recent cascade, half of physicians who pursued clinically unnecessary follow-up cited community norms as motivation, while those with prior lawsuits were particularly driven by fear of another lawsuit. ${ }^{5}$ Altogether, our results suggest the need to motivate cost-conscious, 
pragmatic decision-making throughout training and practice, as well as peer support mechanisms, especially following a malpractice suit. ${ }^{6}$ This study is limited by potential recall bias, though we examine both hypothetical and prior actions. In sum, we find that many physicians reported they would or had pursued equivocal incidental findings for non-clinical reasons and that shifting community norms may be a key solution.

Acknowledgements: The authors thank statistician E. John Orav, $\mathrm{PhD}$ and research assistant Claire Lupo, BBA, for their contributions to this work.

Corresponding Author: Ishani Ganguli, MD, MPH; Harvard Medical School, Boston, MA, USA (e-mail: iganguli@bwh.harvard.edu).

Authors' Contributions All those listed as authors had an active role and significant impact on conceptualizing, performing, analyzing, and/or writing this work.

Funding This work was supported by the Agency for Healthcare Research and Quality (AHRQ) grant number 1RO1HSO23812. This sponsor played no role in the design and conduct of this study, nor in the preparation, review, or approval of the manuscript.

\section{Compliance with Ethical Standards:}

Partners Institutional Review Board approved this study.

Conflict of Interest: The authors declare that they do not have a conflict of interest.

\section{REFERENCES}

1. Deyo RA. Cascade effects of medical technology. Annu Rev Public Heal. 2002;23:23-44.

2. Presidential Commission for the Study of Bioethical Issues. Anticipate and Communicate: Ethical Management of Incidental and Secondary Findings in the Clinical, Research, and Direct-to-Consumer Contexts | December 2013. 2013:1-160. https://bioethicsarchive.georgetown.edu/pcsbi/node/ 3183.html. Accessed May 1, 2019.

3. Zafar HM, Bugos EK, Langlotz CP, Frasso R. "Chasing a Ghost": Factors that Influence Primary Care Physicians to Follow Up on Incidental Imaging Findings. Radiology. 2016;281:567-573.

4. Schwartz AL, Jena AB, Zaslavsky AM, McWilliams JM. Analysis of Physician Variation in Provision of Low-Value Services. JAMA Intern Med. 2019;179:16-25.

5. Rothberg MB, Class J, Bishop TF, Friderici J, Kleppel R, Lindenauer PK. The Cost of Defensive Medicine on 3 Hospital Medicine Services. JAMA Intern Med. 2014;174:1867.

6. Parchman ML, Henrikson NB, Blasi PR, et al. Taking action on overuse: Creating the culture for change. Healthcare. 2017;5:199-203.

Publisher's Note Springer Nature remains neutral with regard to jurisdictional claims in published maps and institutional affiliations. 